\title{
OPTIMASI MINIMUM POLA BAJU KHAS KAIN TENUN SARUNG SAMARINDA MENGGUNAKAN ALGORITMA GREEDY
}

\author{
Hani Subakti ${ }^{1}$, Windu Gata ${ }^{2}$ \\ Magister Ilmu Komputer, STMIK Nusa Mandiri \\ E-mail: 14002626@nusamandiri.ac.id ${ }^{1}$,windu@ nusamandiri.ac.id ${ }^{2}$
}

\begin{abstract}
Abstrak
Baju khas kain tenun sarung Samarinda saat ini sudah menjadi kebutuhan sekunder di dalam aktivitas sehari-hari masyarakat di Kota Samarinda. Dalam pembuatannya baju khas kain tenun sarung Samarinda memerlukan luas bahan kain tenun yang cukup untuk memasangkannya pada pola baju dengan berbagai ukuran tertentu. Penelitian ini memerlukan metode yang tepat guna dalam mengukur luas kain tenun yang dibutuhkan untuk pemasangan pola baju dengan berbagai ukuran yaitu dengan menggunakan algoritma greedy. Algoritma greedy merupakan metode yang tepat untuk memecahkan permasalahan optimasi termasuk pada ukuran kain. Dengan metode yang digunakan ini disinyalisasi dapat mempermudah pada produsen atau pembuat pola baju khas kain tenun sarung Samarinda dalam mengetahui ukuran kain tenun yang dibutuhkannya. Oleh karena itu pada penelitian ini dilakukan beberapa tahapan di antaranya, tahapan pertama menganalisis bagian pola baju berukuran medium, tahap kedua mengukur luas setiap pola pada bagian baju, dan tahap ketiga memasang pola berukuran medium pada bahan kain tenun khas sarung Samarinda dengan mengoptimalkan lebar kain yang ada. Penerapan pola baju kain khas kain tenun sarung Samarinda dengan menggunakan algoritma greedy pada ukuran medium dapat disimpulkan mampu mengoptimalkan penggunaan kain tersebut. Tahapan yang sistematis tersebut dapat mempermudah produsen atau pembuat baju khas kain tenun sarung Samarinda dalam memanfaatkan bahan kain tenun tersebut dengan seminimal mungkin sehingga tidak terjadi pemborosan pada kain tenun sarung Samarinda.
\end{abstract}

Kata kunci: Baju, Khas kain tenun sarung Samarinda, Pola, Algoritma Greedy

\begin{abstract}
Nowadays, the typical clothes of the Samarinda sarong woven cloth have become a secondary requirement in the daily activities of the people in Samarinda City. In making the typical woven cloth, the sarong of Samarinda requires a sufficient area of the woven cloth to attach it to the pattern of clothes of various sizes. This research requires an appropriate method in measuring the area of woven fabric required for the installation of clothing patterns of various sizes, namely by using the greedy algorithm. Greedy algorithm is the right method to solve optimization problems, including the size of the fabric. With the method used, it is indicated that it can make it easier for producers or makers of typical clothes patterns for the Samarinda sarong woven cloth to find out the size of the woven cloth they need. Therefore, in this study several stages were carried out, including the first stage analyzing the medium-sized clothing pattern, the second stage measuring the area of each pattern on the shirt section, and the third stage installing a medium-sized pattern on the woven cloth typical of Samarinda sarong by optimizing the width of the cloth. there is. The application of the typical cloth woven sarong pattern of Samarinda by using the greedy algorithm on the medium size can be concluded to
\end{abstract}


be able to optimize the use of these fabrics. This systematic stage can make it easier for producers or makers of typical Samarinda sarong woven cloth to utilize the woven fabric to the minimum so that there is no waste of the Samarinda sarong woven fabric.

Keywords: Shirt, Typical fabric woven sarong Samarinda, Patterns, Greedy Algorithm

\section{PENDAHULUAN}

Dewasa ini pemakaian sebuah baju yang memiliki ciri khas sebuah daerah menjadi sebuah kebutuhan. Ini pula yang saat ini terjadi di Kota Samarinda. Dari jajaran staf hingga pimpinan di tingkat pemerintahan Kota Samarinda sepakat dihari tertentu memakai baju khas yang terbuat dari kain tenun sarung Samarinda. Dengan berbagai motif desain dan model yang beraneka ragam. Banyak pula pekerja di sektor nonpemerintahan yang menggunakan baju khas kain tenun sarung Samarinda. Hal ini seakan menjadi kebutuhan sekunder bagi para pekerja usia produktif. Baju kerja yang terbuat dari kain tenun sarung Samarinda memang sangat cocok digunakan diberbagai kesempatan. Tidak hanya saat berkantor saja, baju khas kain tenun sarung Samarinda juga sangan cocok untuk digunakan saat menghadiri sebuah pesta karena terlihat mewah. Motif yang muncul dari khas kain tenun sarung Samarinda sangatlah elok dan elegan bila dikenakan. Proses pembuatan baju khas kain tenun sarung Samarinda menjadi tolok ukur kepantasan bagi pemakainya. Sementara itu bahan kain khas kain tenun sarung Samarinda menjadi faktor penentu dan utama. Semakin banyaknya baju khas kain tenun sarung Samarinda yang diproduksi sudah pasti semakin besar luas kain khas kain tenun sarung Samarinda yang dibutuhkan dan ukuranukuran tersebut membuat baju khas kain tenun sarung Samarinda jadi berbeda-beda. Sehingga kurang optimalnya produsen atau pembuat baju khas kain tenun sarung Samarinda dalam menentukan luas yang optimal pada kain khas kain tenun sarung Samarinda yang dibutuhkan. Oleh karena itu perlu solusi yang ditawarkan untuk mewujudkannya diperlukan algoritma greedy.

Algoritma greedy adalah algoritma yang dapat dijadikan solusi melalui langka perlangkah di dalam menyusun kain khas kain tenun sarung Samarinda yang akan disesuaikan dengan pola atau desain yang diharapkan. Di dalam setiap langkah mebuat baju kain khas kain tenun sarung Samarinda tersebut akan dipilih keputusan yang paling optimal. Dengan menggunakan algoritma greedy dapat menentukan bagaimana langkah-langkah serta perhitungan yang pas dan optimal untuk menentukan luas pada suatu kain khas kain tenun sarung Samarinda yang dapat dipasang pola sebuah baju khas kain tenun sarung Samarinda yang dibutuhkan. Berdasarkan dari identifikasi permasalahan yang muncul tersebut dan dengan tujuan penelitian ini agar lebih terarah maka perlu adanya penyusunan rumusan masalah. Rumusan masalah dalam penelitian ini adalah bagaimana algoritma greedy menentukan optimasi minimum pada luas bahan kain khas kain tenun sarung Samarinda yang akan dipasangkan pada pola baju dengan ukuran $\mathrm{m} /$ medium. Dalam penelitian ini hanya membahasa pola baju yang dipasangkan pada ukuran $\mathrm{m} /$ medium. Hal ini dikarenakan batasan masalah yang diteliti.

\section{LANDASAN TEORI}

\subsection{Algoritma Greedy}

Algoritma greedy adalah metode yang cukup popular dalam memecahkan sebuah persoalan khususnya optimasi. Pada dasarnya hanya ada dua macam persoalan optimasi yaitu optimasi maksimal dan optimasi minimal. Algoritma greedy sendiri merupakan algoritma yang memecahkan masalah langkah per langkah dengan baik (Munir, 2011). Di sisi lain sebuah algoritma greedy akan membentuk solusi langkah per langkah (step by step) dengan urutan yang pas. Pada dasarnya Terdapat banyak pilihan yang perlu dieksplorasi pada setiap penentuan langkah solusi. Oleh karena itu, setiap langkah harus disusun keputusan yang terbaik dalam menentukan sebuah pilihan. Keputusan yang telah diambil pada suatu langkah tidak dapat diubah lagi nantinya. Persoalan optimasi (optimization problems) adalah persoalan yang 
menuntut pencarian solusi optimum. Persoalan optimasi ada dua macam yaitu Maksimasi (maximization) dan Minimasi (minimization). Solusi optimum (terbaik) adalah solusi yang bernilai minimum atau maksimum dari sekumpulan alternatif solusi yang mungkin.

\subsection{Skema Umum Algoitma Greedy}

Persoalan sebuah optimasi dalam konteks algoritma greedy disusun atas elemen-elemen sebagai berikut:

a) Himpunan kandidat $\mathrm{C}$

Himpunan kandidat $\mathrm{C}$ ini berisikan elementelement sebagai pembentuk dari solusi pada setiap langkah. Oleh karena itu satu buah kandidat diambil dari himpunannya.

b) Himpunan solusi $S$

Himpunan solusi $\mathrm{S}$ ini berisi kandidatkandidat yang sudah terpilih sebagai solusi dari persoalan. Dengan kata lain himpunan solusi S merupakan himpunan-himpunan bagian dari himpunan kandidat.

c) Fungsi seleksi

Fungsi seleksi ini dapat dinyatakan dengan sebuah predikat seleksi. Hal ini merupakan fungsi pada setiap langkah karena telah memilih kandidat yang paling memungkinkan mencapai solusi optimal. Kandidat yang sudah dipilih pada suatu langkah tidak akan pernah dipertimbangkan kembali pada langkah-langkah selanjutnya.

d) Fungsi kelayakan

Fungsi kelayakan ini dapat dinyatakan dengan predikat layak. Fungsi kelayakan adalah fungsi yang memeriksa apakah suatu kandidat yang telah terpilih mampu memberikan solusi yang baik dan layak. Kandidat ini akan bersama-sama dengan himpunan solusi yang telah terbentuk dan tidak menjadi kendala. Kandidat yang layak pun nantinya dimasukan ke dalam himpunan solusi. Sedangkan untuk kandidat yang tidak layak akan dibuang dan tidak pernah dipertimbangkan lagi.

e) Fungsi objektif

Fungsi objektif ini adalah sebuah fungsi yang mampu memaksimumkan atau pun meminimumkan nilai sebuah solusi (Munir, 2011).

\section{HASIL DAN PEMBAHASAN}

\subsection{Deskripsi Masalah}

Baju khas sebuah daerah khususnya Kota Samarinda memiliki ciri yang tidak dimiliki oleh daerah lain. Baju ini memiliki bahan kain khas kain tenun sarung Samarinda yang sangan elok dan elegan. Kain-kain khas kain tenun sarung Samarinda dengan luas tertentu dapat diasumsikan sebagai wadah yang menampung pola baju kain khas kain tenun sarung Samarinda dengan ukuran tertentu seperti S, M, L, XL, dan XXL. Pola baju kain-kain khas kain tenun sarung Samarinda dengan bagian-bagian yang dibutuhkan seperti bagian badan kanan, badan kiri, leher, tangan kiri dan kanan, saku, dan pola yang lainnya. Setelah diukur dan mengetahui lalu ditentukan ukuran pada setiap bagian pola baju kain khas kain tenun sarung Samarinda dengan menggunakan algoritma greedy. Dengan demikian luas minimum pada bahan kain khas kain tenun sarung Samarinda yang akan dipasang pola dapat diketahui dengan cepat dan mudah.

Pada penelitian ini terdapat kain khas kain tenun sarung Samarinda yang memiliki panjang $1,1 \mathrm{~m}$ dan lebar $1,5 \mathrm{~m}$ yang akan dipasang pada pola baju kain khas kain tenun sarung Samarinda dengan ukuran M/ medium. Pola akan ditaruh pada bagian-bagian pola baju kain khas kain tenun sarung Samarinda dengan ukuran $\mathrm{M}$ / medium. Peneliti hanya memilih ukuran $\mathrm{M} /$ medium dikarenakan batasan penelitian yang dilakukan.

a) Bagian belakang/punggung dari pola bagian belakang atau punggung baju kain khas kain tenun sarung Samarinda dengan ukuran sebagai berikut 78 × 57 $\mathrm{cm}$.

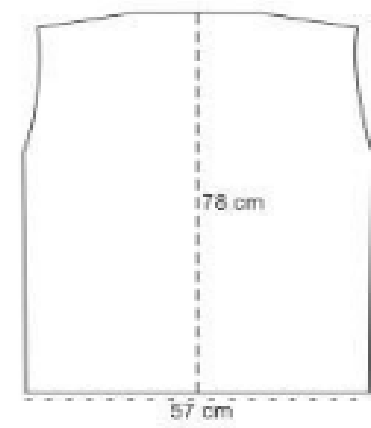

Gambar 1. Bagian belakang/punggung baju dengan kain khas kain tenun sarung Samarinda

b) Bagian badan depan kiri dari pola untuk bagian badan depan sebelah kiri baju kain 
khas kain tenun sarung Samarinda dengan ukuran $70 \times 30 \mathrm{~cm}$

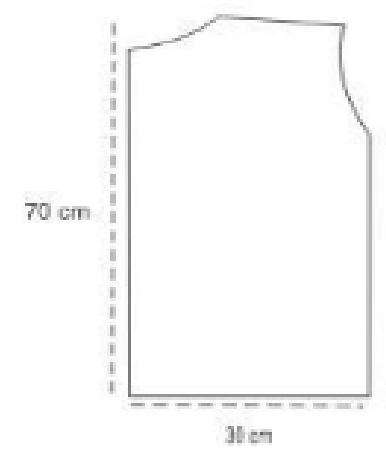

Gambar 2. Bagian badan depan kiri baju kain khas kain tenun sarung Samarinda

c) Bagian badan depan kanan pola untuk bagian badan depan sebelah kanan pada baju kain khas kain tenun sarung Samarinda dengan ukuran $70 \times 30 \mathrm{~cm}$

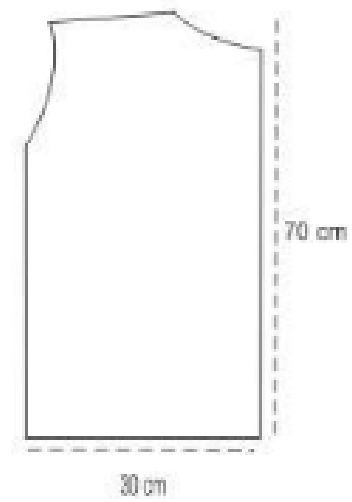

Gambar 3. Bagian badan depan kanan baju kain khas kain tenun sarung Samarinda

d) Bagian tangan kanan/kiri pada pola untuk bagian tangan kanan dengan bentuk dan ukuran yang sama baju kain khas kain tenun sarung Samarinda yaitu 47 x $58 \mathrm{~cm}$

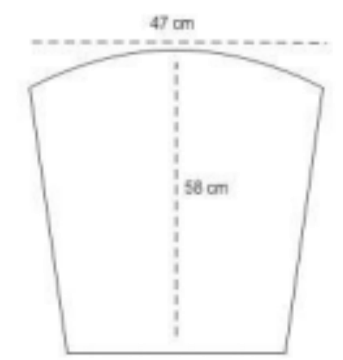

Gambar 4. Bagian Tangan Kanan/Kiri baju kain khas kain tenun sarung Samarinda e) Bagian saku kanan/kiri pada pola untuk bagian saku dengan bentuk yang sama dan ukuran yang sama baju kain khas kain tenun sarung Samarinda yaitu $20 \mathrm{x}$ $18 \mathrm{~cm}$

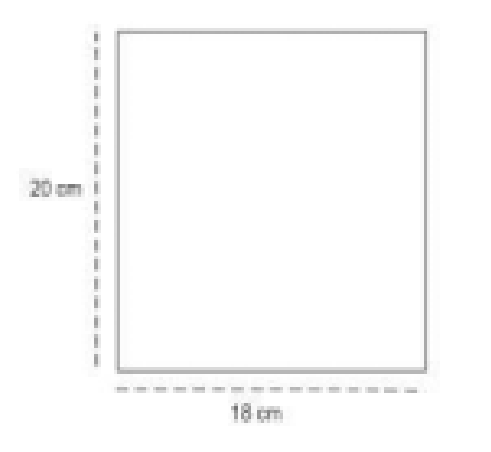

Gambar 5. Bagian Tangan Kanan/Kiri baju kain khas kain tenun sarung Samarinda

\subsection{Implementasi Algoritma Greedy}

Penerapan metode algoritma greedy dapat digunakan pada pola dengan ukuran baju kain khas kain tenun sarung Samarinda ukuran 78 x $57 \mathrm{~cm}$.

Tabel 1. Ukuran pola baju kain khas kain tenun sarung Samarinda dengan ukuran M/ medium.

\begin{tabular}{|c|c|c|c|}
\hline Kode & Nama Pola & Panjang & Lebar \\
\hline \multirow[t]{2}{*}{$\mathrm{Bk}$} & Belakang/Pungg & 78 & 57 \\
\hline & gung baju & & \\
\hline \multirow[t]{2}{*}{ Bdka } & Badan & 70 & 30 \\
\hline & Depan baju & & \\
\hline Bdki & Badan Depan kiri & 70 & 30 \\
\hline Tki & Tangan kiri & 58 & 47 \\
\hline Tka & Tangan Kanan & 58 & 47 \\
\hline Sk1 & Saku 1 baju & 20 & 18 \\
\hline Sk2 & Saku 2 baju & 20 & 18 \\
\hline
\end{tabular}




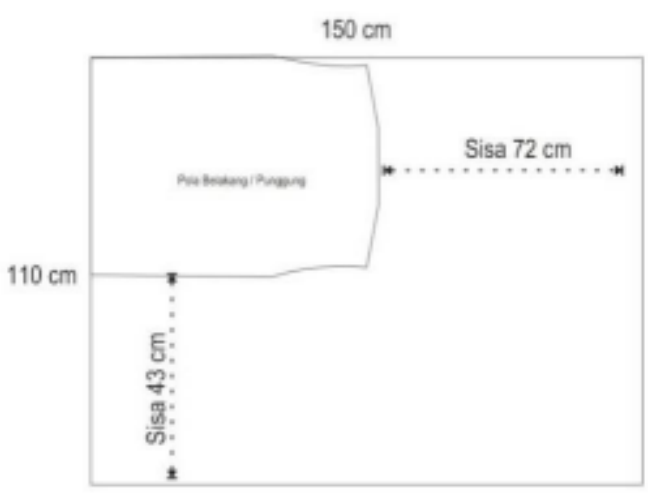

Gambar 6. Pola baju kain khas kain tenun sarung Samarinda

Langkah-langkah algoritma greedy :

1) Untuk sisa panjang kain diambil pola dengan ukuran panjang/lebar yang paling besar dan dapat memaksimalkan sisa panjang bahan baju kain khas kain tenun sarung Samarinda yang ukurannya $72 \mathrm{~cm}$. Berikut merupakan pola-pola dengan lebar atau panjang di bawah $72 \mathrm{~cm}$ :

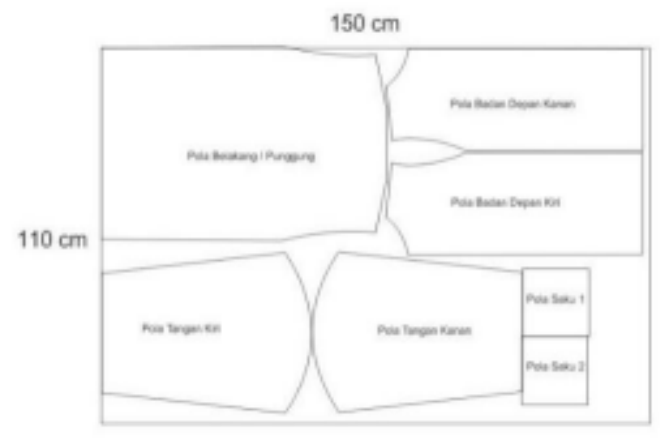

Gambar 7. Pola badan kanan dan kiri baju kain khas kain tenun sarung Samarinda

Sementara itu setelah mengukur pola baju kain khas kain tenun sarung Samarinda yang tersisa di atas, maka pola baju kain khas kain tenun sarung Samarinda yang cocok untuk mengisi sisa panjang yaitu pada pola bagian badan kanan dan kiri karena pola tersebut mempunyai panjang $70 \mathrm{~cm}$ sehingga dapat memaksimalkan sisa panjang pada bahan baju kain khas kain tenun sarung Samarinda.

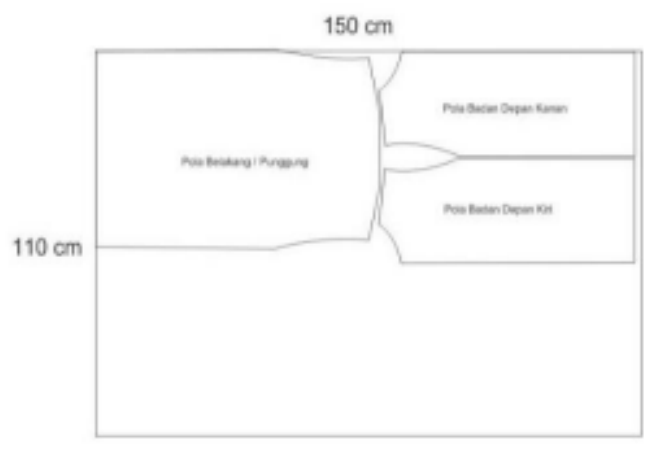

Gambar 8. Pola sisa baju kain khas kain tenun sarung Samarinda

2) Untuk sisa lebar baju kain khas kain tenun sarung Samarinda dapat diambil pola yang tersisa dengan ukuran panjang/lebar yang paling besar dan bisa memaksimalkan sisa lebar bahan baju kain khas kain tenun sarung Samarinda yang sisa yaitu lebar 53 $\mathrm{cm}$. Setelah itu pola-pola dengan lebar atau panjang di bawah $53 \mathrm{~cm}$. Setelah mengukur pola baju kain khas kain tenun sarung Samarinda yang tersisa di atas yaitu pola tangan kanan atau kiri karena pola tersebut mempunyai lebar $47 \mathrm{~cm}$ sehingga dapat memaksimalkan sisa lebar pada bahan baju kain khas kain tenun sarung Samarinda.

\section{SIMPULAN DAN SARAN}

\subsection{Simpulan}

Dalam penelitian ini terdapat kesimpulan yang diproleh. Adapun kesimpulan dari penelitian ini adalah sebagai berikut:

a) Pada Pengukuran pola baju dengan kain khas kain tenun sarung Samarinda terjadi penghematan pada kain dalam membentuk ukuran M/ medium. Hal ini bisa terjadi karena menggunakan pengukuran yang pas dan terstruktur menggunakan algoritma greedy.

b) Algoritma greedy dapat digunakan di dalam menentukan bagaimana luas minimum dari sebuah bahan kain khas kain tenun sarung Samarinda berdasarkan pola baju itu sendiri.

c) Bahan baju khas kain tenun sarung Samarinda yang digunakan dapat diasumsikan sebagai naungan atau wadah untuk menampung pola-pola baju yang 
menggunakan kain khas kain tenun sarung Samarinda.

d) Produsen baju atau pembuat baju yang menggunakan kain khas kain tenun sarung Samarinda dapat menganalisis pola-pola baju lainnya yang dibutuhkan untuk mengukur panjang dan lebar setiap pola baju tersebut.

\subsection{Saran}

Dalam penelitian ini terdapat saran yang bisa diberikan. Adapun saran dari penelitian ini adalah sebagai berikut:

a) Pada penelitian ini perlu penerapan algoritma greedy yang hanya mengatur bagaimana pola baju kain khas kain tenun sarung Samarinda tersebut agar bisa dipasang dan muat pada bahan kain yang tersedia yaitu ukuran $\mathrm{M} /$ medium.

b) Penelitian ini hanya dilakukan pada pola baju kain khas kain tenun sarung Samarinda dengan ukuran M/ medium, untuk selanjutnya dapat dilakukan pada ukuranukuran yang lebih besar dari M/ medium.

\section{DAFTAR PUSTAKA}

Bednorz, W. (2008). Advaces in Greedy Algorithms. Croatia: In-Tech.

Bellman, R. (1957). Dynamic Programming. New Jersey: Princeton University Press.

J. A. Bony and Murty, U. S. R (1976). Graph Theory With Application. Ontario: North- Holland.

Jungnickel, D. (2008). Graphs, Network and Algorithms Third Edition. Germany: Springer.

Munir, R. (2011). Diktat Kuliah IFF2251 (Algoritma Greedy) Strategy Algoritmik. Bandung: Program Studi Informatika. Sekolah Teknik Elektro dan Informatika ITB: Tidak diterbitkan.

Neapolitan, R. dan Naimpour, K. (2011). Foundations of Algorithms Fourth Edition. Canada: Jones and Bartlett Publisher, LLC.

Suyanto. (2010). Algoritma Optimasi Deterministik atau Porbabilitik. Yogyakarta: Graha Ilmu. 